\title{
An Improved Test for Generating Rapid, Accurate, and Reliable Crack Permeability Data for Cementitious Materials
}

\author{
Damian Palin $^{1}$ (D) $\cdot$ Yu Mo ${ }^{2} \cdot$ Virginie Wiktor $^{1} \cdot$ Henk Marius Jonkers $^{1}$
}

Received: 22 January 2018 / Revised: 6 May 2018 / Accepted: 9 May 2018 / Published online: 21 May 2018

(c) The Author(s) 2018

\begin{abstract}
Presented is a modified test for generating crack permeability data for cementitious materials. Single-parallel cracks were generated in mortar specimens. The width of the cracks was analysed through stereomicroscope and computer tomography, and the water permeability of the cracks was determined. Reduction factors and crack flow models were generated, and the reliability of those predictions was assessed. Cracks analysed through stereomicroscope produced reliable crack permeability predictions $\left(r^{2}=0.97-0.98\right)$, highlighting the importance of testing multiple $(\geq 7)$ replicates. The modified test produced accurate cracks (i.e., cracks that were within $20 \mu \mathrm{m}$ of their desired crack width) and was easy to use allowing rapid permeability data (i.e., $10 \mathrm{~h}$ for 21 specimens) to be generated. The modified test will be of great use for those wanting to generate rapid, accurate, and reliable crack permeability data for cementitious materials.
\end{abstract}

Keywords Cementitious materials $\cdot$ Microcracking $\cdot$ Defined crack widths $\cdot$ Water permeability $\cdot$ Reliability $\cdot$ Durability

\section{Introduction}

Reinforced concrete is designed to crack as the embedded steel reinforcement takes over tensile stresses. Cracks can allow the ingress of water and waterborne aggressive agents, having consequences for concrete performance and safety. Water permeability measurements have long been used for assessing the durability [1-5], and more recently for quantifying the healing capacity of cementitious materials [6-11]. The permeability data presented in these studies, though of

Damian Palin

d.palin@tudelft.nl

Yu Mo

moyu@umd.edu

Virginie Wiktor

v.a.c.wiktor-1@tudelft.nl

Henk Marius Jonkers

h.m.jonkers@tudelft.nl

1 Section of Materials and Environment, Faculty of Civil Engineering and Geosciences, Delft University of Technology, Stevinweg 1, 2628 CN Delft, The Netherlands

2 Department of Environmental Science and Technology, University of Maryland, 1426 Animal Sci./Ag. Engr. Bldg, College Park, MD 20742, USA great value, demonstrate considerable variability, making it difficult to compare the data. A test, therefore, for generating rapid, accurate, and reliable crack permeability data would be of great value to the cementitious materials community.

Reliable crack permeability data presuppose the generation of defined crack width geometries. Given the heterogeneous nature of cementitious materials, such geometries are difficult to create in the laboratory. A common method for producing cracks in cementitious specimens is the bending method [11-13]. Cracks are generally produced in reinforced prismatic specimens through three-point or four-point bending. A load is applied to the specimens until bending cracks appear. Though realistic, such cracks have been shown to relax after loading, which makes it difficult to control their final width [13]. Another common method for producing cracks in cementitious specimens is the tensile splitting technique $[1-5,7,8]$. Tensile cracks are generally generated in cylindrical specimens by applying a diametrical load. Linear variable displacement transducers (LVDTs) can then be fitted to specimens in conjunction with a feedback-controlled machine to generate controlled crack width displacements $[1-5,8]$. Cracks generated using this technique, like the bending method, have been shown to relax upon unloading, which makes it difficult to control their final width $[1-4,8]$. It is also difficult with this method to produce single cracks as a result of crack branching $[1,4]$. Furthermore, generating 
crack widths $>0.5 \mathrm{~mm}$ can result in the specimens becoming too fragile for permeability testing $[1,5]$. Reinforcement can be added to the specimens to prevent this "fragility" [4, 14]. This reinforcement, however, has been shown to affect the resultant crack permeability data [4] severely. Moreover, crack permeability studies quite often have demanding setups and long-testing periods. For example, the feedback-controlled tensile splitting method requires a testing machine, computer, LVDTs, etc., making it demanding and expensive to set up $[1-5,8]$. All these setups seem to use glues and/ or rubber coatings to seal specimens for testing $[1-3,5,7$, $9,10]$. Such glues and coatings can be time-consuming to apply and may require many hours to dry, while their poor application if unnoticed could give rise to misleading results. Furthermore, crack permeability studies tend to wait for a steady-state flow to be achieved, that is, for the crack flow to equal the outflow. This means that testing periods can last 90-100 [2, 3, 8] days. Such demanding permeability setups and long-testing periods have likely restricted the number of replicates tested, exacerbating any variability in the crack permeability data.

Recently, our group introduced a test for generating crack permeability data for cementitious specimens [10]. The test consisted of a novel method for creating defined crack widths in cementitious specimens and a simple and rapid permeability setup. Mortar cylinders were cast having two diametrically opposite grooves running down their sides. The specimens were split from groove to groove and spacers fitted to create defined parallel crack width geometries. The speed of the permeability setup meant that multiple replicates could be easily tested giving statistical power to the resultant crack permeability data. The ability of the test to create defined crack width geometries coupled with the easy testing of multiple replicates meant that reference permeabilities for cracked specimens could be generated against which autogenously healed cracked specimens could be quantified. Following this work, it was clear that a number of modifications could be made to improve the speed, accuracy, and reliability of the test. The current paper presents the modified test. To gauge for any improvement as a result of the modifications both the unmodified and modified tests were tested and compared.

\section{Experimental Programme}

Table 1 shows the main differences between the unmodified test and the modified test. To gauge for any improvement as a result of the modifications, both tests in the current study were tested and compared. Cracks intended to be 0.2 , 0.4 , and $0.6 \mathrm{~mm}$ wide were generated in mortar specimens by both tests. Cracks widths were assessed through computer tomography (CT) and stereomicroscope, and the flow
Table 1 Main differences between the unmodified and modified tests

\begin{tabular}{lll}
\hline Aspect & Test & \\
\cline { 2 - 3 } & Unmodified & Modified \\
\hline Cracking & Instron machine & Vise \\
Cracked specimens & Separated apart & Kept together \\
Crack width spacers & Hand machined perspex & Metal gauges \\
Permeability cell & Silicone sealant & O-rings and retainer \\
\hline
\end{tabular}

Table 2 Mix design for mortar specimens

\begin{tabular}{ll}
\hline Constituent & $\begin{array}{l}\text { Amount } \\
\left(\mathrm{kg} \mathrm{m}^{-3}\right)\end{array}$ \\
\hline $\begin{array}{l}\text { Cement (CEM III/B } \\
\text { 42.5 N LH) }\end{array}$ & 494 \\
Water & \\
Water cement ratio & 0.5 \\
Sand fraction (mm) & \\
1-2 & 608 \\
$0.5-1$ & 426 \\
$0.25-0.5$ & 167 \\
$0.125-0.25$ & 319 \\
\hline
\end{tabular}

of water through these cracks was also determined. Crack flow models were then generated and the reliability of those predictions assessed.

\subsection{Specimen Preparation}

\subsubsection{The Unmodified Test}

Mortar cylinders $(60 \mathrm{~mm}$ long and with a diameter of $33.5 \mathrm{~mm}$ ) were cast from blast furnace slag (BFS) cement (CEM III/B 42.5 N LH, ENCI) in accordance with EN 101511 [15]. The applied mortar mix design is shown in Table 2. The cylinders, having two diametrically opposite grooves ( $2 \mathrm{~mm}$ wide and $3 \mathrm{~mm}$ deep) running down their side were cast in specially designed silicone moulds. $24 \mathrm{~h}$ after casting, the specimens were carefully removed from their moulds, tightly sealed in polyethylene plastic bags, and kept at room temperature for a total curing period of 28 days. Following curing, each mortar cylinder was wrapped in polyethylene film and steel rods placed at their grooves. Specimens with the rods were then placed between the platens of an Instron 8872 servohydraulic testing machine (Instron Corp., Canton, MA, USA) and compressive loads applied until they split diametrically from groove to groove. Specimens were unwrapped, separated apart, and hand machined Perspex spacers fitted at the grooves. The halves were then fitted back together to achieve three crack width series $0.2,0.4$, and $0.6 \mathrm{~mm}$ wide; and each series consisting of seven specimens each. With the spacers fitted, Plex 7742 and liquid 
Pleximon 801 (Evonik Röhm GmbH, Darmstadt, Germany) were mixed; applied along part of the grooves and allowed to dry. The spacers were then removed and the remainder of the grooves glued creating specimens with defined crack width geometries. Images of the cracks were taken at the specimens' ends with a Leica MZ6 (Leica, Nussloch, Germany) equipped with LAS v.40 software, with a resolution of $2.2(1000 / 447) \mu \mathrm{m}$. Crack boundaries were defined by eye and the crack area measured in Photoshop (Adobe Systems, San Jose, CA, USA), and the average crack width calculated for each specimen. The first two specimens of each series were also subject to crack volume analysis through CT (Phoenix|X-ray, GE, Wunstorf, Germany) with a resolution of $16 \mu \mathrm{m}$. Each $360^{\circ}$ scan consisting of 1440 tomographic images took $90 \mathrm{~min}$. Scans were then opened in VG Studio Max 2.0 (Volume Graphics GmbH, Heidelberg, Germany) to calculate the crack width. A virtual cylinder was created within the software package to encompass the crack volume. This cylinder was created by drawing a circle with the ellipse tool and stretching the circle into a cylinder. The crack volume within the cylinder was isolated with the volume analyser tool by eye and the crack volume known. The width of the crack could then be determined by dividing the crack volume by the height and diameter of the virtual cylinder. Here, we define crack width accuracy as the difference between the mean measured and the desired crack width (i.e., measurement $\mathrm{A}$ is more accurate than measurement $\mathrm{B}$ if the value of $A$ is closer to the desired crack width than $B$ ).

\subsubsection{The Modified Test}

A few key differences exist between the modified and unmodified tests when preparing the specimens. A vise was used to apply a load to the steel rods as opposed to the Instron machine. A vise was used to split the specimens for its simplicity and ease of use. When splitting the specimens with the vice, great care was taken to keep the two halves together to prevent material loss. Metal feeler gauges (accuracy: $\pm 0.01 \mathrm{~mm}$ ) were used to define the crack widths rather than hand machined Perspex spacers.

\subsection{Permeability Setup}

\subsubsection{The Unmodified Test}

Specimens for the unmodified test were silicone-glued into sections of polyvinyl chloride pipe $(60 \mathrm{~mm}$ long with an internal diameter of $33.5 \mathrm{~mm}$ ), and the silicone allowed to cure for $24 \mathrm{~h}$ providing a watertight permeability cell (Fig. 1a). Seven permeability columns were set up to run in parallel and a permeability cell fitted to the bottom of each column (Fig. 2). Synthetic seawater was prepared (the composition of which is in Table 3) and poured into reservoirs at the top of each column. Synthetic seawater was used as this study is part of a larger study looking to develop bacteria-based self-healing concrete for application in low-temperature marine environments. Taps in each reservoir were released initiating the flow of water. The test was run for $10 \mathrm{~min}$ and any water flowing through the cracks was collected in catchment buckets, and the water collected weighed. The test duration was based on how, in a previous study, an almost steady-state flow was achieved after $10 \mathrm{~min}$ [10]. The water level of each column was manually maintained between 1 and $1.05 \mathrm{~m}$ giving an almost constant water head of $0.1 \mathrm{bar}$.
Fig. 1 Schematic showing a cross section through the permeability cells of: a unmodified test and $\mathbf{b}$ modified test
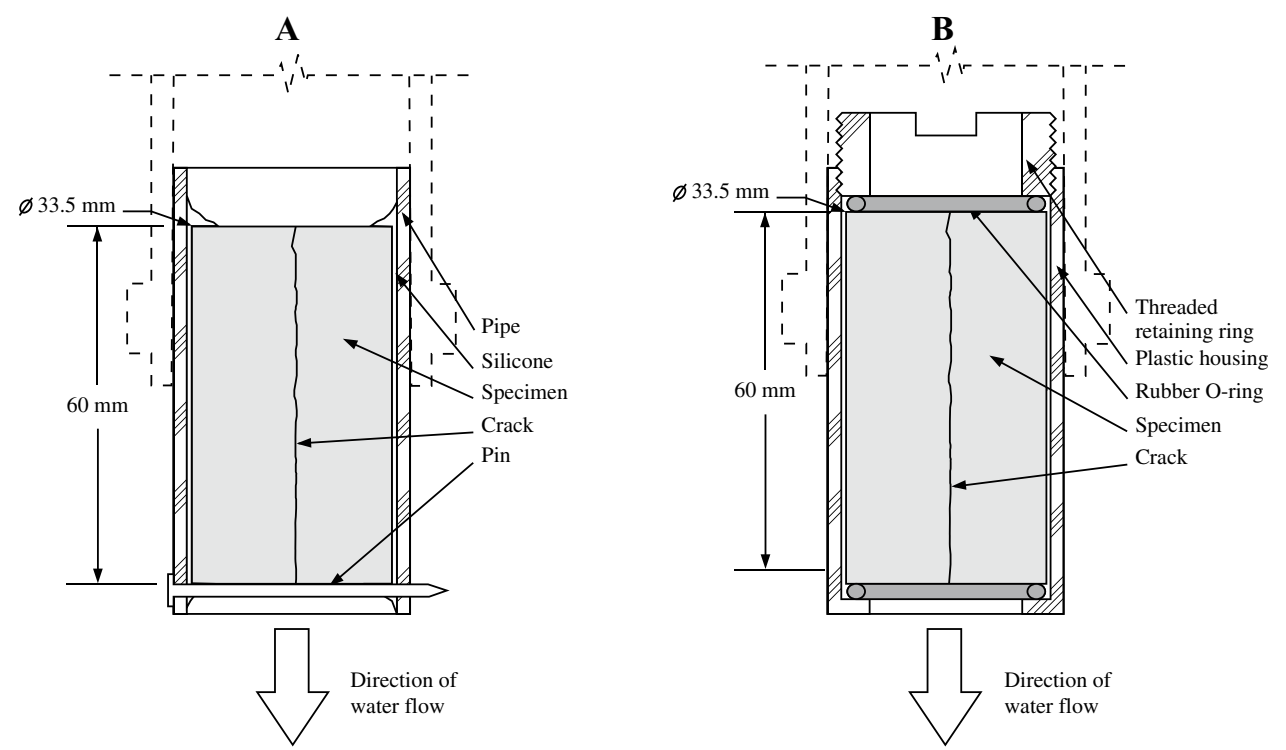
Fig. 2 Photo (a) and schematic (b) of the permeability setup
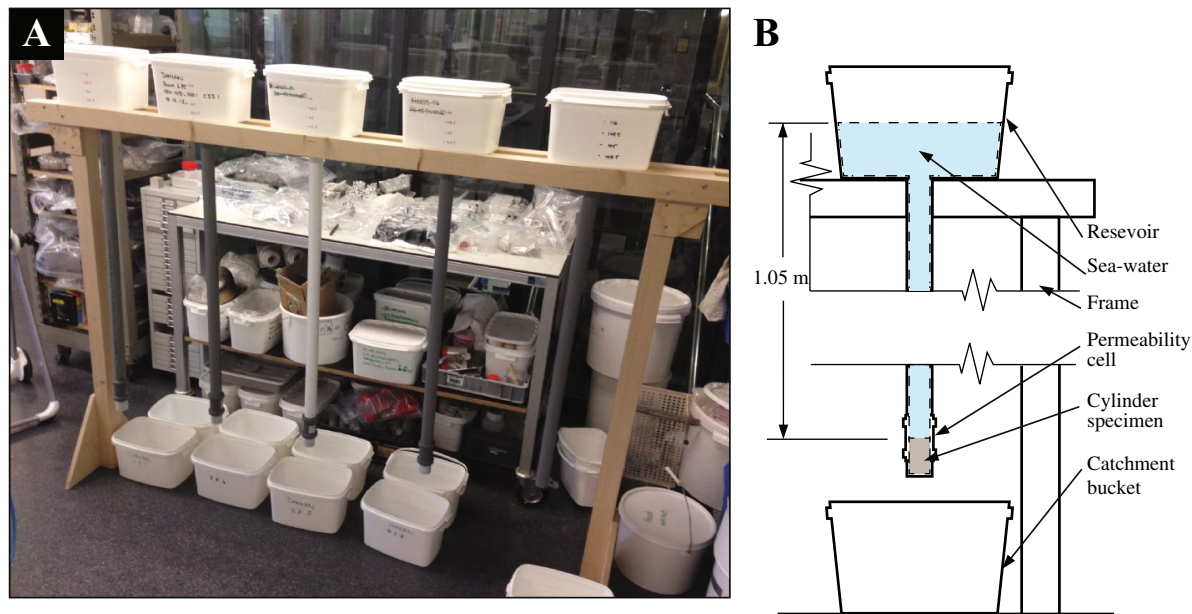

Table 3 Synthetic seawater composition based after the major constituents of seawater [16]

\begin{tabular}{lc}
\hline Compound & Amount $\left(\mathrm{g} \mathrm{l}^{-1}\right)$ \\
\hline $\mathrm{NaHCO}_{3}$ & 0.19 \\
$\mathrm{CaCl}_{2} \cdot 2 \mathrm{H}_{2} \mathrm{O}$ & 1.47 \\
$\mathrm{MgCl}_{2} \cdot 6 \mathrm{H}_{2} \mathrm{O}$ & 10.57 \\
$\mathrm{Na}_{2} \mathrm{SO}_{4} \cdot 10 \mathrm{H}_{2} \mathrm{O}$ & 9.02 \\
$\mathrm{KCl}$ & 0.75 \\
$\mathrm{NaCl}$ & 24.08 \\
\hline
\end{tabular}

\subsubsection{The Modified Test}

The only difference between the permeability setups of the unmodified and modified tests was the permeability cells used. Machined out polyethylene, the permeability cell of the modified test $(60 \mathrm{~mm}$ long with internal diameters of $35 \mathrm{~mm}$ ) was designed to house a specimen with two rubber O-rings located at its upper face and lower face, such that when a retaining ring was tightened the cell became watertight (Fig. 1b).

\subsection{Crack Flow Model}

A common model used to estimate crack water flow is one derived from the laminar flow of incompressible Newtonian fluids between smooth parallel plates. The model often referred to as Poiseuille's law, can be computed using the following formula (Eq. 1) [17]:

$q_{0}=\frac{\Delta p \cdot l \cdot w^{3}}{12 \cdot \eta \cdot d}$

where $q_{0}=$ water flow between smooth parallel plates $\left(\mathrm{m}^{3} \mathrm{~s}^{-1}\right), \Delta p=$ differential water pressure between crack inlet and outlet $\left(\mathrm{N} \mathrm{m}^{-2}\right), l=$ crack length (is the length of the crack across the face of the cylindrical specimen) (m), $w=$ Crack width (is the distance between the crack faces) (m), $d=$ Crack depth (is the distance between the two faces of the cylindrical specimen) (m), and $\eta=$ absolute viscosity $\left(\mathrm{Ns} \mathrm{m}^{-2}\right.$ ).

Smooth parallel crack plates, however, do not occur in cementitious materials. Factors such as roughness and tortuosity reduce the crack water flow making it less than estimated according to Eq. (1). To account for roughness and tortuosity, Eq. (1) can be modified to include an empirically derived reduction factor (Eq. 2) [7]:

$q_{r}=\frac{\xi \cdot \Delta p \cdot l \cdot w^{3}}{12 \cdot \eta \cdot d}$

where $q_{r}=$ water flow through cementitious cracks $\left(\mathrm{m}^{3} \mathrm{~s}^{-1}\right)$ and $\xi=$ reduction factor.

The reduction factor can be estimated if all the other parameters are measured during the experiment.

In this study, we estimate the reduction factors for four crack flow models: the unmodified test whose crack widths were analysed through CT or stereomicroscope, and modified test whose crack widths measured through CT and stereomicroscope. The quality of the models will be indicated by: the closeness of the $r^{2}$ to 1 ; the closeness of the observed values to the predicted value; and the reliability of the predicted values as indicated by the narrowness of the confidence interval (CI) and prediction interval (PI) of the predicted values.

\section{Results}

\subsection{Crack Width Analysis}

Table 4 shows CT and stereomicroscope crack width analysis for cracks produced by the unmodified and modified 
Table 4 Crack width analysis through computer tomography and stereomicroscopy of cracks generated by the unmodified and modified methodologies

\begin{tabular}{|c|c|c|c|c|c|c|}
\hline \multirow[t]{4}{*}{ Analysis } & \multicolumn{6}{|c|}{ Crack widths } \\
\hline & \multicolumn{3}{|c|}{ Unmodified } & \multicolumn{3}{|c|}{ Modified } \\
\hline & \multicolumn{3}{|c|}{ Desired crack width $(\mu \mathrm{m})$} & \multicolumn{3}{|c|}{ Desired crack width $(\mu \mathrm{m})$} \\
\hline & 200 & 400 & 600 & 200 & 400 & 600 \\
\hline \multicolumn{7}{|c|}{ Computer tomography } \\
\hline $\bar{x}(\mu \mathrm{m})$ & 232 & 399 & 495 & 233 & 382 & 601 \\
\hline$D(\mu \mathrm{m})$ & 33 & 1 & 105 & 33 & 18 & 1 \\
\hline \multicolumn{7}{|c|}{ Stereomicroscopy } \\
\hline $\bar{x}(\mu \mathrm{m})$ & 160 & 335 & 511 & 222 & 397 & 564 \\
\hline$D(\mu \mathrm{m})$ & 40 & 65 & 89 & 22 & 3 & 36 \\
\hline$S(\mu \mathrm{m})$ & 10 & 42 & 25 & 51 & 50 & 35 \\
\hline
\end{tabular}

$\bar{x}$ mean of the measured values, $D$ difference between mean measured and the desired crack width, $S$ estimated standard deviation methods. CT and stereomicroscope analysis showed that cracks produced by the modified test were, on average, within $20 \mu \mathrm{m}$ of the desired crack width, versus $55 \mu \mathrm{m}$ for the unmodified test; and that the standard deviations and hence repeatability of the crack widths analysed through stereomicroscope were somewhat similar for both tests. CT analysis of the cracks generated by both tests demonstrated that the crack faces were relatively parallel and hence very well suited to Poiseuille's law (Eq. 1). Figure 3 shows images taken via CT and stereomicroscope of representative cracked specimens.

\subsection{Permeability Data}

Figure 4 shows the experimental permeability data plotted against the modelled data (Eq. 2) for the unmodified test whose cracks were analysed through $\mathrm{CT}$, the modified test whose cracks were analysed through CT, the unmodified test whose cracks were analysed through stereomicroscope, and the modified test whose cracks were analysed through stereomicroscope. The experimental data are well described by the modelled data $\left(r^{2}=0.97-0.98\right)$. The unmodified and modified tests whose cracks were analysed through stereoscope produced similarly narrow CIs and PIs (Fig. 4c, d), and narrower CIs and PIs than those analysed through CT (Fig. 4a, b). The modified test whose cracks were analysed through CT produced narrower CIs and PIs than the unmodified test. The reduction factors were computed with Eq. (2) based on the experimental data. The average reduction factor for the unmodified test whose cracks were analysed through CT was $0.15 \pm 0.03$; for the modified test whose cracks were analysed through CT, it was $0.12 \pm 0.02$; for the unmodified test whose cracks were analysed through stereomicroscope, it was $0.17 \pm 0.02$; and for the modified test whose cracks were analysed through stereomicroscope, it was $0.15 \pm 0.01$.

\subsection{Improved Speed of the Modified Test}

The modified test allowed crack permeability data to be produced 30\% quicker than unmodified test. This improved speed coming as a result of the splitting method and permeability cells used. Using a simple vise meant that 21 specimens could be split in $1 \mathrm{~h}$ versus the Instron machine which took $3.5 \mathrm{~h}$. The permeability cell of the unmodified test allowed the same number of specimens to be fitted/sealed in $1.5 \mathrm{~h}$ versus the cell of the unmodified test which took $4 \mathrm{~h}$. Furthermore, the silicone used to seal the specimens in the cell of the unmodified test took $24 \mathrm{~h}$ to dry, while the cell of the modified test could be used promptly.

\section{Discussion}

To gauge for any improvement as a result of the modifications, both tests in the current study were tested and compared. Cracks of defined widths were generated in mortar specimens by both tests and the flow of water through those cracks determined. Crack flow models were generated and the accuracy and the reliability those predictions assessed. The accuracy of the four models was very high $\left(r^{2}=0.97-0.98\right)$, and the reliability of the predictions indicated by the narrowness of their CIs and PIs. The crack flow models generated by the unmodified and modified tests whose cracks were analysed through stereomicroscope (Fig. 4c, d) produced more reliable predicted values than those cracks analysed through CT (Fig. 4a, b). This reliability is attributable to the greater number of replicates that could be easily analysed through stereomicroscopy versus $\mathrm{CT}$, and how more sample replicates leads to more reliable estimates [18]. When looking at the predicted values generated by the unmodified and modified tests whose cracks were analysed through CT, we can see that the modified test 
Fig. $3 \mathrm{CT}$ and stereomicroscope images of cracked specimens. CT cross-sectional images of specimens with cracks intended to be a $200 \mu \mathrm{m}, \mathbf{c} 400 \mu \mathrm{m}$, and e $600 \mu \mathrm{m}$ wide; and stereomicroscope images of specimens with cracks also intended to be b $200 \mu \mathrm{m}$, d $400 \mu \mathrm{m}$, and $\mathbf{f}$ $600 \mu \mathrm{m}$ wide
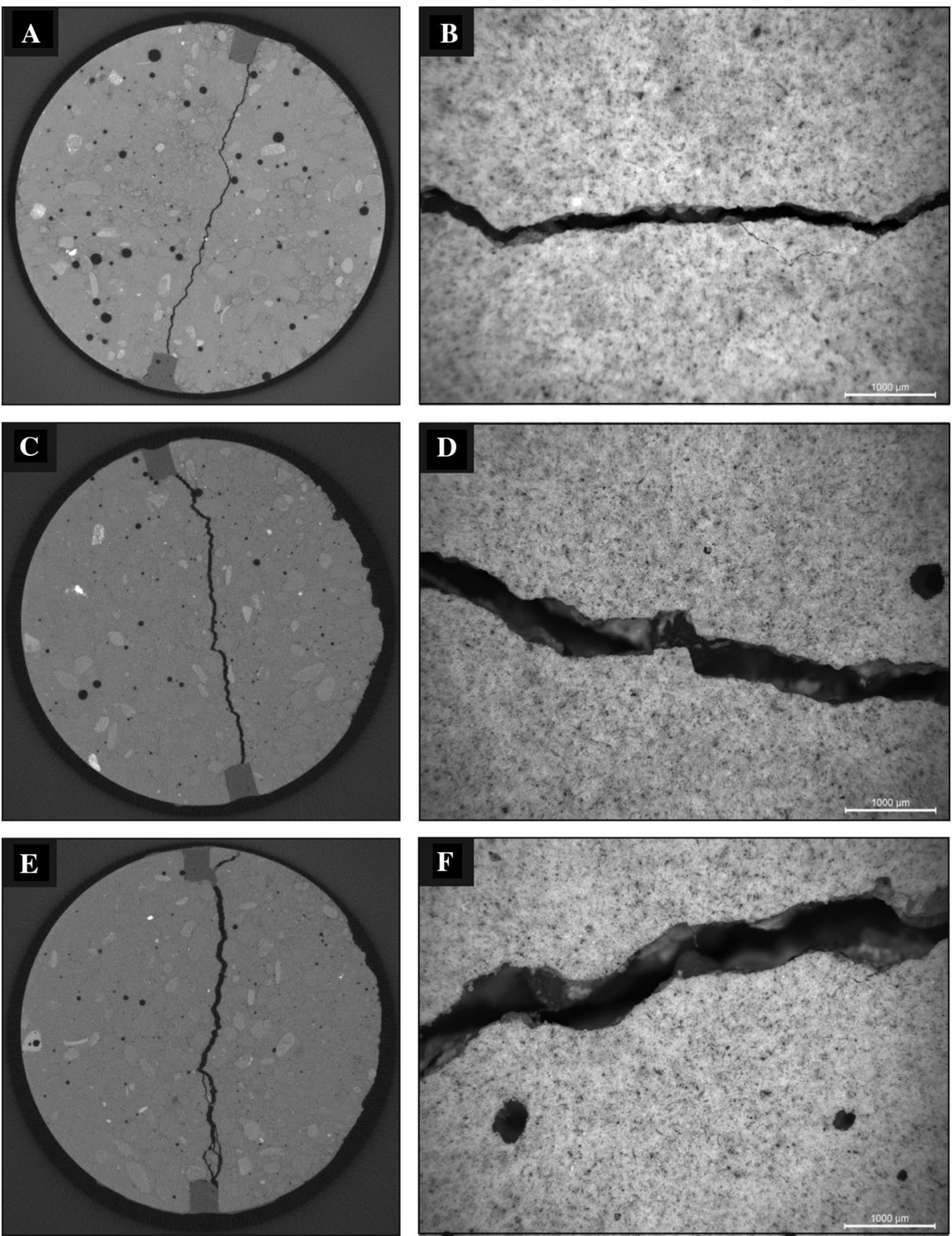

produced a more reliable predicted value than the unmodified test (Fig. 4a, b). This difference likely stems from differences between the perceived and true crack geometries of the two tests, and how the modified test was able to limit factors such as material loss, poor sealing, and crack obstruction (silicone in the cracks). The two tests whose cracks were analysed through stereomicroscopy produced similarly reliable predicted values, demonstrating the value of testing larger sample sets ( $\geq 7$ samples) (Fig. 4c, d). Even though the reliability of the predicted values generated by the unmodified and modified tests whose cracks were analysed through stereomicroscope was similar (Fig. 4d, e), cracks generated by the modified test were more accurate than those generated by the unmodified test (Table 4). This increased accuracy coming as a result of using more accurate crack width spacers in the form of the metal gauges.
Increased crack width accuracy-according to the model (Eq. 1) - means more accurate crack permeability data.

Crack permeability studies often have demanding setups and long-testing periods [1-5, 7-10]. Both the unmodified and modified tests produced crack permeability data relatively quickly. The modified test, however, was $30 \%$ quicker at producing the permeability data for 21 specimens. This improved speed coming as a result of not having to use the Instron machine to split the specimens and the ease and effectiveness with which the modified permeability cell could be used. Analysis of the cracks through stereomicroscopy was quicker than through CT; this, of course, is highly dependent on the CT equipment used. Furthermore, being able to use crack permeability data generated after $10 \mathrm{~min}$ water flow is far quicker than the many hours sighted in the literature $[2,3,8]$. 
Fig. 4 Experimental data plotted against predicted values for: a unmodified test whose cracks were analysed through CT: b modified test whose cracks were analysed through CT; $\mathbf{c}$ unmodified test whose cracks were analysed through stereomicroscope; and $\mathbf{d}$ modified test whose cracks were analysed through stereomicroscope. Symbols represent the observed values; lines represent the predicted values; the darker-shaded areas flanking the lines represent the $95 \%$ confidence intervals, and the lighter areas flanking the lines represent the $95 \%$ prediction intervals. The $R$-squared $\left(r^{2}\right)$ values for the models are also indicated

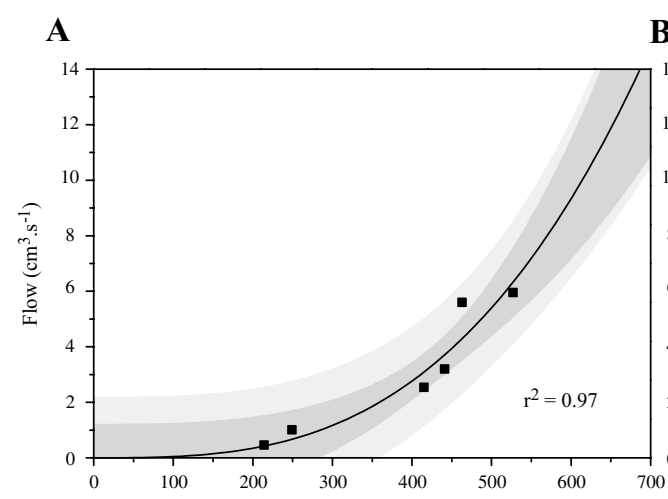

B

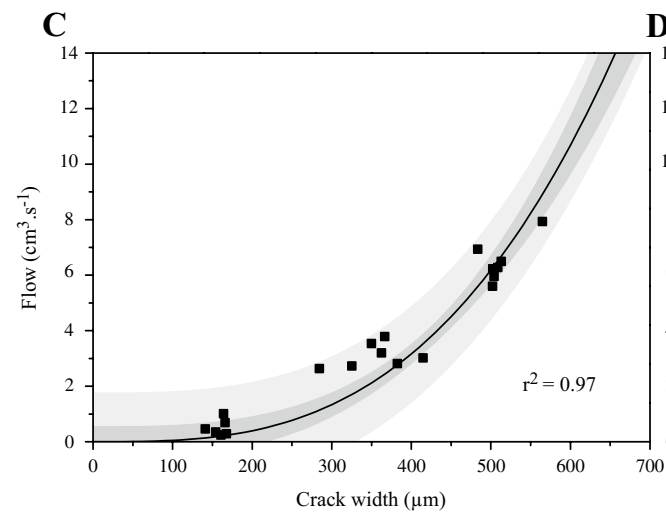

D

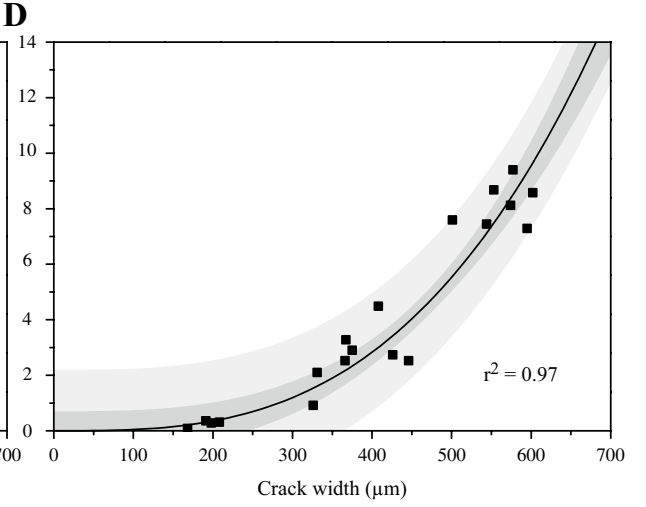

\section{Conclusion}

Following a previous study [10], we have present a modified test for generating rapid, accurate, and reliable crack permeability data for cementitious materials. Cracks were generated in mortar specimens by both tests, the accuracy of the cracks assessed through stereomicroscopy and CT, and the flow of water through the cracks determined. Crack flow models were generated and the accuracy and reliability of those predictions assessed.

- The accuracy of the four models was all very high $\left(r^{2}=0.96-0.98\right)$, while the models generated by those cracks analysed through stereomicroscope (i.e., larger sample sets) were more reliable.

- The modified test produced more accurate cracks than the unmodified test, with the modified test producing cracks that were within $20 \mu \mathrm{m}$ of their desired width and the unmodified test producing cracks that were $55 \mu \mathrm{m}$ greater than their desired width.

- The modified test was 30\% quicker at producing the crack flow data than the unmodified test.

- The simplicity/speed of the permeability test means that relatively large numbers of replicates can be easily tested, which is important for generating reliable crack permeability data for cementitious materials.

- The modified test can be of great use for those studying the crack healing capacity and durability of cementitious materials; and has been used to quantify the autogenous healing capacity of a bacteria-based self-healing cementitious composite for application in low-temperature marine environments [19].

Acknowledgements The authors would like to thank Arjan Thijssen for his help with the CT analysis and Gerrit Nagtegaal during the design and construction of the permeability setup, while the research leading to these results has been funded through the European Union Seventh Framework Programme (FP7/2007-2013) under Grant agreement $n^{\circ}$ 290308 - SheMat.

Funding European Commission.

Open Access This article is distributed under the terms of the Creative Commons Attribution 4.0 International License (http://creativeco mmons.org/licenses/by/4.0/), which permits unrestricted use, distribution, and reproduction in any medium, provided you give appropriate credit to the original author(s) and the source, provide a link to the Creative Commons license, and indicate if changes were made.

\section{References}

1. Wang K, Jansen DC, Shah SP, Karr AF (1997) Permeability study of cracked concrete. Cem Concr Res 27:381-393

2. Aldea C-M, Shah S, Karr A (1999) Permeability of cracked concrete. Mater Struct 32:370-376 
3. Aldea C-M, Shah SP, Karr A (1999) Effect of cracking on water and chloride permeability of concrete. J Mater Civ Eng 11:181-187

4. Rapoport J, Aldea C-M, Shah SP, Ankenman B, Karr A (2002) Permeability of cracked steel fiber-reinforced concrete. J Mater Civ Eng 14:355-358

5. Picandet V, Khelidj A, Bellegou H (2009) Crack effects on gas and water permeability of concretes. Cem Concr Res 39:537-547

6. Clear C (1985) The effects of autogenous healing upon the leakage of water through cracks in concrete. Cem Concr Assoc 1985:559

7. Edvardsen C (1999) Water permeability and autogenous healing of cracks in concrete. ACI Mater J Am Concr Inst 96:448-454

8. Aldea C-M, Song W-J, Popovics JS, Shah SP (2000) Extent of healing of cracked normal strength concrete. J Mater Civ Eng 12:92-96

9. Reinhardt HW, Jooss M (2003) Permeability and self-healing of cracked concrete as a function of temperature and crack width. Cem Concr Res 33:981-985

10. Palin D, Jonkers HM, Wiktor V (2016) Autogenous healing of sea-water exposed mortar: quantification through a simple and rapid permeability test. Cem Concr Res 84:1-7

11. Tziviloglou E, Wiktor V, Jonkers HM, Schlangen E (2016) Bacteria-based self-healing concrete to increase liquid tightness of cracks. Constr Build Mater 122:118-125
12. Schieß1 P, Raupach M (1997) Laboratory studies and calculations on the influence of crack width on chloride-induced corrosion of steel in concrete. ACI Mater J 94:56-62

13. Şahmaran M (2007) Effect of flexure induced transverse crack and self-healing on chloride diffusivity of reinforced mortar. J Mater Sci 42:9131-9136

14. Reinhardt H-W, Jooss M (2003) Permeability and self-healing of cracked concrete as a function of temperature and crack width. Cem Concr Res 33:981-985

15. BS EN 1015-11 (1999) Methods of test for mortar for masonry, Part 11: determination of flexural and compressive strength of hardened mortar. European Committee for Standardization, Brussels,

16. Stumm W, Morgan JJ (1996) Aquatic chemistry: chemical equilibrium and rates in natural waters. Wiley, New York

17. Huitt J (1956) Fluid flow in simulated fractures. AIChE J $2: 259-264$

18. Rowe $\mathrm{P}$ (2015) Essential statistics for the pharmaceutical sciences. Wiley, Berlin

19. Palin D, Wiktor V, Jonkers HM (2017) A bacteria-based selfhealing cementitious composite for application in low-temperature marine environments. Biomimetics 2:13 